\title{
Climate Regime Effects on Pacific Herring Growth Using Coupled Nutrient-Phytoplankton-Zooplankton and Bioenergetics Models
}

\author{
KenNeth A. Rose* \\ Department of Oceanography and Coastal Sciences, \\ Louisiana State University, Baton Rouge, Louisiana 70803, USA
}

Bernard A. Megrey

National Marine Fisheries Service, Alaska Fisheries Science Center, 7600 Sandpoint Way NE, Bin C15700, Seattle, Washington 98115-0070, USA

Douglas Hay

Pacific Biological Station, Fisheries and Oceans Canada, Nanaimo, British Columbia V9R 5K6, Canada

\author{
FRANCISCO WERNER \\ Department of Marine Sciences, University of North Carolina, \\ Chapel Hill, North Carolina 27599-3300, USA
}

\section{JAKE SCHWEIGERT}

\author{
Pacific Biological Station, Fisheries and Oceans Canada, Nanaimo, British Columbia V9R 5K6, Canada
}

\begin{abstract}
We used a nutrient-phytoplankton-zooplankton (NPZ) model coupled to a fish bioenergetics model to simulate the weight-at-age responses of Pacific herring Clupea pallasii to climate regimes. The NPZ model represents the daily dynamics of the lower trophic levels by simulating the uptake and recycling dynamics of nitrogen and silicon and the photosynthesis and grazing interactions of multiple functional groups of phytoplankton and zooplankton. The bioenergetics model simulates the number and mean weight of Pacific herring for each of 10 age-classes. Three zooplankton groups simulated in the NPZ model provide estimates of the prey used to determine the consumption component of the herring bioenergetics model. We used a spawner-recruit relationship to estimate the number of new age-1 individuals joining the herring population every year. The coupled models were applied to the coastal upwelling area off the west coast of Vancouver Island. Model simulations were performed to isolate the effects of each of four documented climate regimes on Pacific herring weights at age. The climate regimes differed in the environmental variables used in the spawner-recruit relationship as well as in the water temperature, mixed-layer depth, and nutrient influxing rate used by the NPZ model. In agreement with general opinion and with the Pacific herring data from the west coast of Vancouver Island, the model-predicted estimates of weight at age, recruitment, and spawning stock biomass were highest in regime 1 (1962-1976), intermediate in regime 2 (1977-1988), and lowest in regime 3 (1989-1999). Insufficient time has passed to adequately document the conditions and herring responses in regime 4 (1998-2002). The overall regime effect on weights at age was a mix of recruitment effects and lower trophic level effects that varied in direction and magnitude among the four regimes. Coupling bioenergetics models to physics and food web models is the next challenge in understanding and forecasting how climate change will affect fish growth and population dynamics.
\end{abstract}

The effects of climate regime shifts on fish population dynamics have received increasing attention in the past decade. A climate regime can be defined as a persistent state in climate, ocean, and biological systems, with a regime shift being an abrupt, nonrandom change from one state to another (Beamish

\section{* Corresponding author: karose@1su.edu}

Received July 7, 2005; accepted March 24, 2006 Published online February 14, 2008 et al. 2004). Interannual variation can occur within a regime, but the climate conditions within regimes are relatively consistent and persistent compared with the magnitude of change that occurs between regimes (King 2005). In the Pacific Ocean, and more recently in the Atlantic Ocean, decadal-scale climate regimes have been documented (Hurrell and van Loon 1997; Miller and Schneider 2000). The focus has been on how physical and environmental conditions vary among regimes and how these conditions work their way up 
the food web (Benson and Trites 2002). Biological responses to regime shifts, especially the responses of upper trophic levels, often lag or are confounded by other processes and events (Miller and Schneider 2000). While there are many linkages between regimes and fish population responses, indirect food web responses and the complex life history and longevity of many fish species complicate easy detection of regime-shift effects on fish populations (Benson and Trites 2002; Beamish et al. 2004). The same regime shift can have opposite effects on the same fish species in different geographic areas, and opposite effects on different fish species within the same geographic area (Benson and Trites 2002). Lower trophic level models coupled with fish growth models may provide an approach for better understanding how climate conditions under different regimes can influence fish population dynamics.

Bioenergetics modeling offers an informative and useful approach for simulating the growth of fish in response to changing environmental conditions. Bioenergetics modeling has evolved in several directions over the past decades (Ney 1990, 1993; Hansen et al. 1993). Bioenergetics modeling focuses on simulating the weight of an individual fish over time using a massbalance equation of weight-dependent and temperaturedependent terms for energetic gains and losses. A major factor in the continued development of the bioenergetics approach was the availability of a userfriendly software package (Hanson et al. 1997) and associated training workshops (Johnson 1992). Bioenergetics models configured with equations like those in the software manual are often referred to as "Wisconsin models" (Ney 1990). Classical bioenergetics models simulate the growth of individual fish over time and use simple cohort dynamics to scale the consumption of an individual to the cohort or population level (e.g., Hartman and Brandt 1995). Subsequent extensions to the basic bioenergetics model included prediction of the effects of migratory fish on nutrient dynamics (e.g., Gottlieb 1998), representation of contaminant effects on fish growth (e.g., Beyers et al. 1999), generation of static spatial maps showing the potential growth rate of fish due to spatial variation of water temperature and prey concentrations (e.g., Hondorp and Brandt 1996), and use as the basis for daily growth in full life cycle, individual-based fish population and community dynamics models (e.g., McDermot and Rose 1999). Recently, Harvey (2005) used a bioenergetics model to determine the energy needed for growth and reproduction of northern California blue rockfish Sebastes mystinus over their 30-year lifetime under baseline conditions and with El Niño-Southern Oscillation (ENSO) events occurring every 3-7 years.
An area ripe for exploration is the coupling of bioenergetics models to other models to examine climate effects on fish growth and population dynamics. Improvements in measurement techniques, such as monitoring of the activity via telemetry of individuals, has helped improved the components of the bioenergetics model (e.g., Cooke et al. 2001). As the components improve, we see bioenergetics models being coupled to lower trophic level (LTL) models to better understand and forecast how climate affects fisheries. This paper is an example of such a coupling; we use coupled nutrient-phytoplankton-zooplankton (NPZ) and bioenergetics models to investigate the effects of climate regimes on the weight at age of Pacific herring Clupea pallasii. We expect a rapid increase in these types of couplings as information on the linkage between climate, water quality, and fish continues to accumulate (Runge et al. 2005). Recent issues related to fish population dynamics seem to gravitate toward harvesting (Pauly et al. 1998) and habitat (Benaka 1999). Focus on such issues has generated research initiatives that are becoming ecosystem oriented, with increasing attention paid to the role of climate change.

The NPZ model represents the daily dynamics of the LTL by simulating the uptake and recycling dynamics of nitrogen and silicon and the photosynthesis and grazing interactions of multiple functional groups of phytoplankton and zooplankton. The herring bioenergetics model is formulated using the Wisconsin model, and is imbedded in a simple age-structured population dynamics model. The NPZ and bioenergetics models are solved simultaneously, predicted zooplankton concentrations from the NPZ determining the consumption by Pacific herring, and herring consumption, egestion, and excretion affecting the dynamics of the NPZ model. The coupled models are applied to the upwelling system off the west coast of Vancouver Island (WCVI). We use the coupled models to predict herring weights at age under environmental conditions representative of four regime periods documented in the eastern North Pacific Ocean.

\section{Pacific Herring and Climate Regimes}

\section{Life History}

We focused on the Pacific herring of southern British Columbia, which comprised two spawning populations, one from WCVI and the other from the Strait of Georgia (SOG). Northern British Columbia herring are composed of three other spawning stocks: Queen Charlotte Islands, Prince Rupert, and Central Coast. These five populations spawn in different areas that cluster within each of the southern or northern 
groupings, and fisheries managers treat these five stocks separately in their assessments (Hay et al. 2001). We used information for the WCVI and the SOG stocks in our analysis because adults of these two commingle on their summer feeding grounds.

Southern British Columbia Pacific herring spawn in early March in inter- and subtidal areas of sheltered inlets, sounds, and bays, the WCVI and SOG stocks returning to their respective spawning areas. Adults of both stocks then leave their spawning grounds and commingle in their summer feeding grounds in the shelf waters $(<200 \mathrm{~m}$ deep) off the west coast of Vancouver Island (near the La Perouse Bank area), where most of each year's annual growth increment occurs (Hay et al. 1988; Tanasichuk 1997).

Pacific herring eggs adhere to vegetation and other hard substrates in the spawning areas and after 2-3 weeks hatch into yolk sac larvae; the yolk sac larval stage lasts about 1 week. Larvae metamorphose into juveniles about 2-3 months after hatching (Lassuy 1989). Juveniles remain inshore near their spawning areas, progressively moving into deeper nearshore waters during their second year until the summer of their third year, when juveniles from both stocks join the adults and move onto shelf waters. Every fall, adults move progressively inshore from their summer feeding grounds on the shelf until they reach their respective nearshore spawning grounds for spawning in March of the next year (Hay et al. 2001).

\section{Regime Periods in the Eastern North Pacific Ocean}

While the strength of regime shifts can vary in magnitude among geographic regions (Francis et al. 1998; King 2005), there is general agreement that significant regime shifts occurred in the eastern North Pacific Ocean in 1925, 1947, 1977, 1989, and possibly 1998 (Benson and Trites 2002). Evidence is still accumulating about the 1998 regime shift (Bograd et al. 2000; Batten and Welch 2004). Available information on these regimes and their effects on fish populations and fisheries management for the North Pacific were recently synthesized by King (2005). For the analyses in this paper, we examined the data and configured our coupled models to correspond to four climate regimes that we refer to as regimes $1-4$, corresponding to 1962-1976 (regime 1), 1977-1988 (regime 2), 1989-1997 (regime 3), and 1998-2002 (regime 4).

The environmental and biological conditions for the California Current system and associated WCVI area differed among the four regime periods (MacCall et al. 2005). Regime 1 was cool and had weak stratification, a shallow mixed-layer depth, and probably strong upwelling, resulting in a period of high primary and secondary productivity. Regime 3 was the warmest, having strong stratification, a deep mixed-layer depth, and weak upwelling. Regime 3 was characterized by low primary and secondary productivity. In a general sense, regime 2 was intermediate between regimes 1 and 3. Although warmer than regime 1 , regime 2 was still a period of relatively high secondary productivity. Regime 4 is recent and ongoing and an ENSO event occurred in 1998 and a La Niña event occurred in 1999; regime 4 conditions still are uncertain.

While phytoplankton and zooplankton productivity were higher in regimes 1 and 2 than in regime 3 , the differences involved changes in species composition as well as biomass (e.g., Mackas et al. 2004). In response to the shifts from regime 2 to 3 and 3 to 4 , species composition and zooplankton biomass changed off WCVI, but some of the major euphasiids in the southern California Current have shown no clear change in abundance in response to recent regimes (Brinton and Townsend 2003).

\section{Fish Responses to Regimes in the Eastern North Pacific Ocean}

Coherent population dynamics of fish species have been documented between oceans and among geographic regions (production domains) within an ocean (Francis et al. 1998; Benson and Trites 2002). Kawasaki (1992) found simultaneous variation in annual catches of Japanese, California, and Chilean sardine populations between about 1910 and 1990 . Hollowed and Wooster $(1992,1995)$ examined recruitment time series for stocks of Pacific herring, northern anchovy Engraulis mordax, and groundfish (e.g., flatfishes and rockfishes) across production domains within the North Pacific Ocean. The relative strength of year-classes in several groundfish species, ranging from the California Current to the Bering Sea, was related to cool and warm eras: warm conditions were necessary but not sufficient for good recruitment. Other examples of fish population responses to regimes in the North Pacific Ocean can be found in Beamish (1995).

Recruitment and the population abundances of coastal fish species in the California Current system and Canada's Pacific coast have varied among the four regime periods. Two recent reviews used available data on recruitment, catch, and other indicators of population status to characterize whether conditions were relatively good or bad for fish in different climate regimes. Beamish et al. (2004) examined the eight major fisheries off Canada's Pacific coast, and MacCall et al. (2005) did a similar analysis for major fisheries in the California Current system. Both characterized conditions as "good" or "improving" during regime 
2 and as "bad" during regime 3 for all fisheries except that for the Pacific sardine Sardinops sagax.

The relationship between Pacific herring population dynamics and regime shifts is suggestive but not definitive. Within the eastern North Pacific Ocean, Williams and Quinn (2000a) identified 3 to 6 groupings among 14 different herring stocks based on the temporal coherence of their annual recruitment and weights at age. They concluded that these groupings reflected temporal synchrony and suggested that largescale oceanographic phenomena have a large influence. Schweigert et al. (2002) examined the mean weight at age of 4-year-olds and the condition factor and annual growth increments of 3- to 6-year-old herring for about 10 eastern North Pacific herring stocks for 1940-2000. They found the expected latitudinal patterns (e.g., older age of maturation in the north), instances of synchrony in growth among some but not all populations, and weak but suggestive correlations of growth with ocean climate indices such as the Pacific Decadal Oscillation. Beamish et al. (2004) concluded that the response of Canada's West Coast herring to regime shifts was less obvious than for other species owing to the fact the movements by Pacific hake Merluccius productus shifted predation pressure, causing top-down (rather than the more tractable bottom-up) effects on the herring.

\section{WCVI and SOG Data}

We examined WCVI and SOG herring data to compare estimates of weights at age, adult summer biomass, spawning stock biomass (SSB), and recruitment across the four regimes (see Schweigert 2004). We used the mean weight at age 4 as an indicator of herring body size because Pacific herring are fully recruited to the sampling gear by age 4 and there are sufficient samples of weights for all years (Schweigert et al. 2002). We also show the mean weight at age of 10 -year-old fish, even though the number of samples is limited, as confirmation of any patterns seen in the age4 weights. We used numbers at age 3 as a measure of recruitment (Williams and Quinn 2000a). Adult biomass on the summer feeding grounds was estimated (similar to Tanasichuk 1997) by adding annual catch to the SSBs of the WCVI and SOG stocks, and dividing by the area of the offshore habitat. A single set of weights at age was derived for the southern British Columbia herring by combining information from WCVI and SOG. We used SSB and recruitment information from the WCVI stock.

The changes in mean weight at ages 4 and 10, recruitment, and SSB among regimes fit with the expected pattern for the WCVI stock, but adult summer biomass was confounded by changes observed in the
SOG stock (Figure 1). Mean weight at age for 4- and 10-year-old fish for the southern British Columbia group appeared to have generally declined (Figure 1a, b). Recruitment and the SSB of the WCVI stock were higher in regimes 1 and 2 and lower in regimes 3 and 4 (Figure 1c, d). In contrast, adult summer biomass was relatively stable or increasing throughout the four regimes (Figure 1e). Adult summer biomass remained high because, while the WCVI SSB declined, the SOG SSB increased during the 1990s (McFarlane et al. 2001). We use a coupled NPZ and herring bioenergetics models to isolate the cumulative and long-term regime effects on the weights at age of WCVI herring.

\section{Model Description}

Pacific herring growth was simulated by means of a bioenergetics model coupled to the North Pacific Ecosystem Model for Understanding Regional Oceanography (NEMURO) NPZ model (Megrey et al. 2007). The coupled models simulated nutrients, plankton, and herring growth in a single well-mixed spatial box with the NPZ configured for the coastal upwelling area off Vancouver Island that serves as the summer feeding grounds of southern British Columbia herring. The numbers of individual herring and their mean weight were followed in each of 10 age-classes for 41 years. We used a spawner-recruit relationship to estimate the number of new age- 1 individuals to be added to the population every year. The NEMURO model simulated the daily concentrations of various forms of dissolved and particulate nitrogen and silicon; small and large phytoplankton groups; and small, large, and predatory zooplankton groups. The three zooplankton groups simulated in the NEMURO model provided the prey for determining the consumption component of the herring bioenergetics model. Herring consumption, in turn, acted as a mortality term on the zooplankton, and herring excretion and egestion contributed to the nitrogen recycling dynamics of the NEMURO model. The NEMURO and herring bioenergetics models comprised a system of ordinary differential equations that were solved simultaneously. The coupled models were described in detail in Megrey et al. (2007).

\section{NEMURO Nutrient-Phytoplankton-Zooplankton Model}

The NEMURO model implemented in this paper simulated the dynamics of the nutrient-phytoplanktonzooplankton food web in a single, well-mixed spatial box that represents the surface layer of the water column (Yamanaka et al. 2004; Kishi et al. 2007). The food web was represented with 11 state variables: nitrate $\left(\mathrm{NO}_{3}\right)$, ammonium $\left(\mathrm{NH}_{4}\right)$, small phytoplankton (PS), large phytoplankton (PL), small zooplankton 

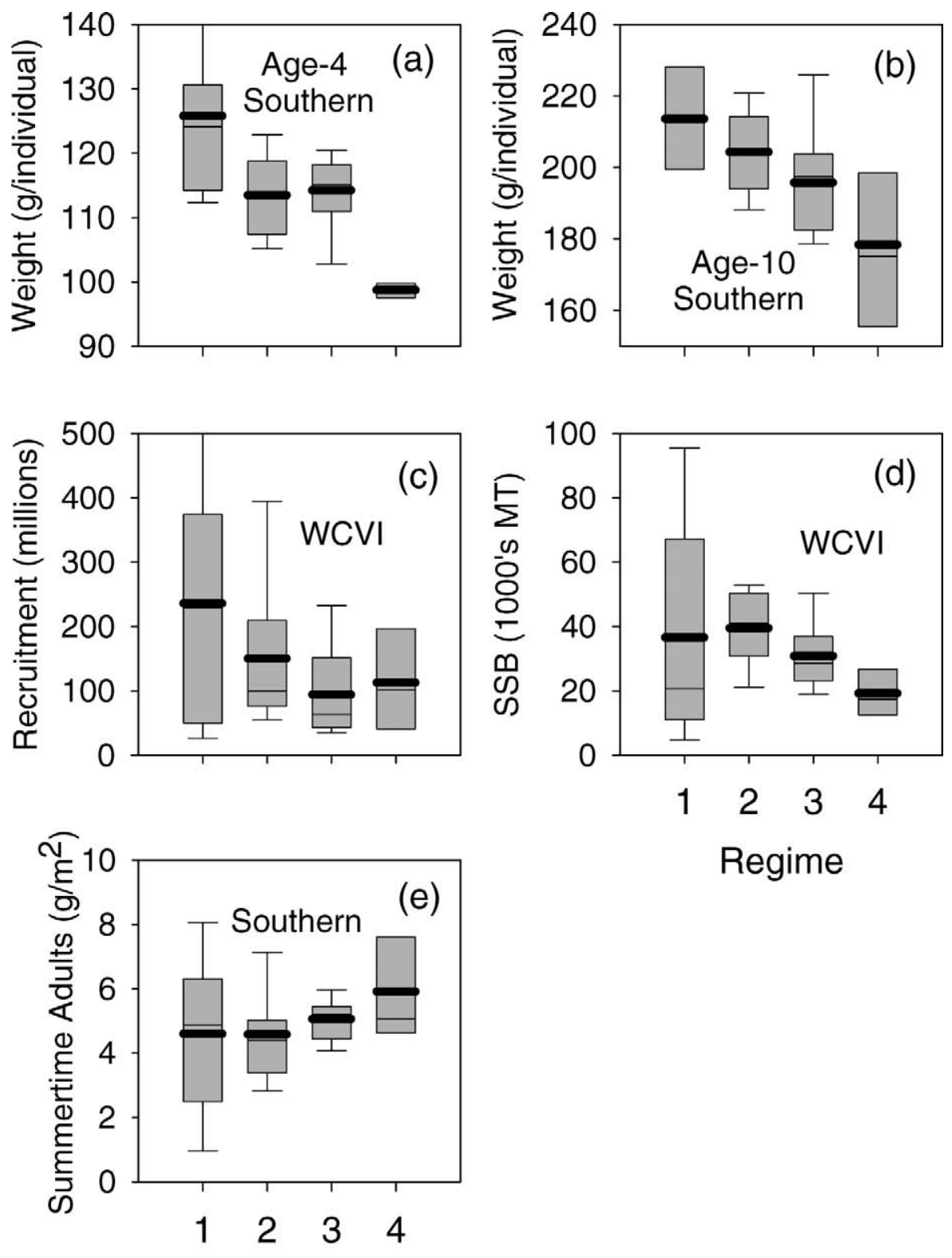

\section{Regime}

\section{Regime}

FIGURE 1.-Observed values of (a) weight at age 4, (b) weight at age 10, (c) recruitment, (d) spawning stock biomass (SSB; $\mathrm{MT}=$ metric tons), and (e) summer adult biomass for southern British Columbia Pacific herring during four regime periods (see text). Southern British Columbia herring comprise two stocks, one along the west coast of Vancouver Island (WCVI) and one in the Strait of Georgia (SOG). The box shows the 25th and 75th percentiles, and the whiskers show the 10th and 90th percentiles; the thin line is the median, and the thick line is the mean.

(ZS), large zooplankton (ZL), predatory zooplankton $(\mathrm{ZP})$, particulate organic nitrogen (PON), dissolved organic nitrogen (DON), particulate organic silicate (Opal), and silicate $\left(\mathrm{Si}[\mathrm{OH}]_{4}\right)$. All NEMURO state variables were tracked in the units of micromoles of nitrogen per liter $(\mu \mathrm{mol} / \mathrm{L})$. The driving variables were the annual cycles of daily water temperature, daily incident solar radiation, and the mixed-layer depth (and associated fluxes of nutrients from below into the modeled box). 
The rate of change of each state variable was expressed as the sum of process rates that affected that state variable. Photosynthesis, respiration, excretion, predation by zooplankton in the model, and other mortality (not accounted for by simulated zooplankton predation) affected each phytoplankton state variable. Grazing, egestion, excretion, predation by zooplankton, and other mortality affected each zooplankton state variable. Nutrient state variables were reduced by photosynthesis uptake; increased by various combinations of phytoplankton and zooplankton respiration, excretion, and mortality; and converted among nutrient forms via first-order, temperature-dependent decomposition reactions. Phytoplankton photosynthesis, respiration, and mortality, and zooplankton grazing and other mortality, were all temperature-dependent. Parameters were expressed as the rates that would occur at $0^{\circ} \mathrm{C}$, and $Q_{10}$ functions (ratio of rate at one temperature to its rate at $10^{\circ} \mathrm{C}$ less) were used to adjust these rates each day based on the simulated water temperature. Photosynthesis also depended upon the average light (integrated over the water column) and nitrate and ammonium concentrations, and photosynthesis of large phytoplankton (diatom-like) also depended on silicate. Grazing by zooplankton was dependent on the concentrations of its prey using a formulation in which an Ivlev parameter governs how quickly maximum grazing rates are approached with increasing prey concentrations.

The version of NEMURO used here was configured and calibrated to approximately represent a coastal upwelling system similar to that off of WCVI (Rose et al. 2007). The upwelling features and lower trophic levels of the WCVI area have been well studied (Robinson and Ware 1999; Tanasichuk 2002; Mackas et al. 2004). We formulated functions that generated incident solar radiation and daily water temperatures representative of the WCVI area (Figure 2a, b). Mixedlayer depth, which defined the thickness of the surface layer in the simulated spatial box, was set to $80 \mathrm{~m}$ for September 26 to March 30, and to a specified shallower regime-specific depth for April 9 to September 6 (Robinson et al. 1993). Linear interpolation was used over $10 \mathrm{~d}$ for each of the transitions between the $80-\mathrm{m}$ depth and, depending on the regime, the $22-30-\mathrm{m}$ depths (Figure 2c). Flux of nitrate into the modeled box was computed as an exchange rate times the difference between the concentration in the modeled box and 25.0 $\mu \mathrm{mol} / \mathrm{L}$. We coupled the nitrate flux into the modeled box to the changes in the mixed-layer depth by assuming the computed flux applied when the mixedlayer depth was $80 \mathrm{~m}$, and by using five times the computed flux whenever the mixed-layer depth was less than $80 \mathrm{~m}$. Because of the shallow waters in this
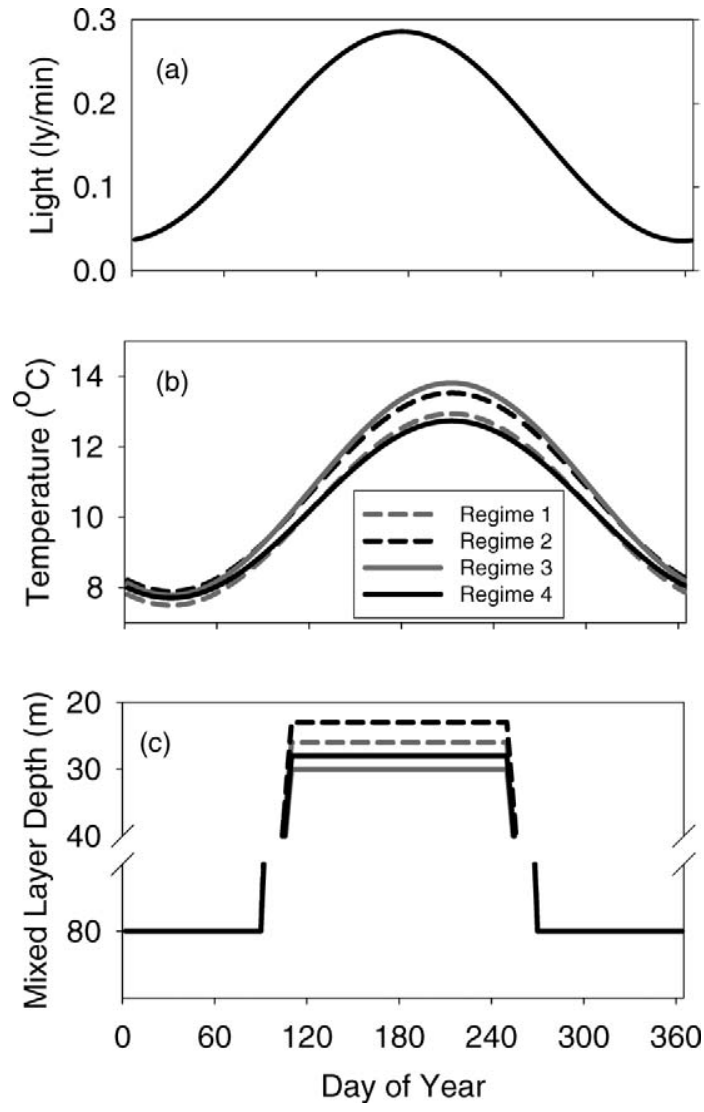

FIGURE 2.-Daily values of the (a) incident light, (b) water temperature, and (c) mixed-layer depth used in the NEMURO nutrient-phytoplankton-zooplankton model for Pacific herring. Daily temperature was also used in the bioenergetics model. Four separate lines, corresponding to the four regime periods, are shown for daily temperature and mixed-layer depth. Incident light is in langleys (ly)/min, where 1 ly is $1,366 \mathrm{~W} / \mathrm{m}^{2}$ and $1 \mathrm{~W}=1 \mathrm{~J} / \mathrm{sec}$.

coastal environment, we eliminated the seasonal vertical migration of the large zooplankton group used in other versions of NEMURO (Kishi et al. 2007); large zooplankton was always present in our modeled spatial box.

NEMURO was calibrated to field data for nitrate, chlorophyll, and zooplankton concentrations collected for the WCVI and California Current areas (Rose et al. 2007). Monthly averages of field data collected from 1991 to 2001 were used to form a typical annual cycle of monthly concentrations of nitrate, total phytoplankton, and small, large, and predatory zooplankton. Rose et al. (2007) used both manual adjustment of parameter values and automated calibration to obtain a reasonable fit of the NEMURO model to the monthly field data. 
We use the calibrated parameter values for NEMURO reported in Rose et al. (2007) in this paper.

\section{Pacific Herring Model}

The Pacific herring model followed the number of individuals and average weight of an individual in each of 10 age-classes. These estimates of numbers at age for each stock are derived from Fisheries and Oceans Canada annual stock assessment reports (e.g., Schweigert 2004). Mean weights at age are estimated from samples routinely collected each year. The simulated average weight of an individual in each age-class was updated with a bioenergetics model, with consumption a function of the zooplankton densities simulated by the NEMURO model. Numbers of individuals in each age-class were decreased each day based on natural and fishing mortality rates. Each year, we used the estimates of Pacific herring spawning biomass (herring age 3 and older) in March and, with annual values of environmental conditions, predicted the number of new individuals (recruitment) that entered as age- 1 individuals in June of that same year. The herring model used units of grams wet weight per cubic meter ( $\mathrm{g}$ wet weight $/ \mathrm{m}^{3}$ ); we converted between the NEMURO units $(\mu \mathrm{mol} / \mathrm{L})$ and the herring model units (g wet weight/ $\mathrm{m}^{3}$ ) assuming that dry weight was $20 \%$ of wet weight and nitrogen was $7 \%$ of dry weight.

Growth.-The growth rate in weight (W; g [wet weight]) of an individual Pacific herring was computed from the equation

$$
\frac{d W}{d t}=[C-(R+S+F+E)] \cdot \frac{\mathrm{CAL}_{z}}{\mathrm{CAL}_{f}} \cdot W,
$$

where $C$ is the realized consumption rate, $R$ is the respiration rate, $S$ is specific dynamic action, $F$ is the egestion rate, $E$ is the excretion rate, $\mathrm{CAL}_{z}$ is the energy density of zooplankton $(\mathrm{J} / \mathrm{g})$, and $\mathrm{CAL}_{f}$ is the energy density of herring $(\mathrm{J} / \mathrm{g})$. The units of $C, R, S, F$, and $E$ are grams of prey per gram of fish per day. The ratio of zooplankton to herring caloric densities converted all of the process rates from that unit to grams of fish per gram of fish per day. The caloric density of herring varied over the year (Megrey et al., in press). Realized consumption rate $(C)$ depended on a maximum consumption rate and the simulated zooplankton densities from the NEMURO model.

The maximum consumption rate and respiration rate were computed as functions of weight and temperature, while the egestion rate, excretion rate, and specific dynamic action were computed based on realized consumption. The herring bioenergetics model was configured using modified versions of the usual formulations in the Wisconsin model (Hanson et al.
1997). We started with the formulations derived by Rudstam (1988) for Baltic Sea Atlantic herring Clupea harengus and tailored the formulations based upon new information on herring energetics and for the eastern North Pacific environment (Klumb 2002). Various versions of Rudstam's original model have been tested using field data and have been used to estimate food consumption by Baltic Sea herring (Arrhenius and Hansson 1994; Arrhenius 1998) as well as to assess the quality the nursery areas used by North Sea Atlantic herring (Maes et al. 2005). Our modifications (Table 1) focused on deriving parameter values specific to age- 0 , age-1, age-2, and older life stages, and adjusting the temperature-related parameters, swimming-speed component of respiration, and seasonal energy densities for Pacific herring using studies published since the Rudstam (1988) paper. Rather than the usual application of the Wisconsin bioenergetics model in which the one determines the fraction of maximum consumption needed to fit known beginning and ending weights, we used a functional response relationship to determine realized consumption based on zooplankton concentrations (see Megrey et al. 2007). The same daily temperatures that were used for the NEMURO model were also used for the herring bioenergetics calculations.

Realized consumption was computed using a multispecies functional response (Rose et al. 1999) with the small, large, and predatory zooplankton as prey types, that is,

$$
C_{j}=\frac{C_{\mathrm{MAX}} \cdot \frac{\mathrm{PD}_{j} \cdot v_{i j}}{K_{i j}}}{1+\sum_{k=1}^{n} \frac{\mathrm{PD}_{k} \cdot v_{i k}}{K_{i k}}},
$$

where $C_{j}$ is the consumption rate of the $j$ th zooplankton group (small, large, and predatory zooplankton for $j=$ 1,2 , and 3 , respectively) by the $i$ th Pacific herring, $\mathrm{PD}_{j}$ is the density of the $j$ th zooplankton group (g wet weight $/ \mathrm{m}^{3}$ ) on each day, $C_{\text {MAX }}$ is the maximum consumption rate $\left(\mathrm{g}\right.$ prey $\cdot \mathrm{g}$ fish $\left.^{-1} \cdot \mathrm{d}^{-1}\right), v_{i j}$ is the vulnerability of the $j$ th zooplankton group to the $i$ th herring, and $K_{i j}$ is the half-saturation coefficient of the $j$ th zooplankton group to the $i$ th herring (g wet weight/ $\mathrm{m}^{3}$ ). The terms $v$ and $K$ have subscripts indicating that the vulnerability and half-saturation coefficients are specific to particular fish sizes or ages. Vulnerabilities were specified (Table 1) based on general descriptions of ontogenetic shifts in herring diets (e.g., Hay et al. 2001). Consumption by the herring, represented by $C$ in equation (1), is the sum up the consumption rates over the three zooplankton groups $\left(C=\Sigma C_{j}\right)$. 
TABLE 1.-Parameter values used in the Pacific herring bioenergetics model. When a single value is given, it applies to fish of all ages. When two values are given, they are for different water temperatures $\left(<9^{\circ} \mathrm{C}\right.$ and $\left.\geq 9^{\circ} \mathrm{C}\right)$ but apply to fish of all ages. When three values are given, they apply to age-0, age-1, and age- 2 and older fish, respectively. The swimming speed component of metabolism does not apply to age-0 fish $\left(d_{R}=0\right.$ so that the values of $a_{A}, b_{A}$, and $c_{A}$ do not matter for age-0 fish).

\begin{tabular}{|c|c|c|}
\hline Parameter & Description & Value \\
\hline \multicolumn{3}{|c|}{ Consumption } \\
\hline$a_{C}$ & Intercept for $C_{M A X}$ at $($ te $2+$ te 3$) / 2$ & 0.642 \\
\hline$b_{C}^{c}$ & Weight exponent for $C_{\mathrm{MAX}}$ & -0.256 \\
\hline tel 1 & Temperature for $x k 1^{a}$ MAX & $1,1,1$ \\
\hline te 2 & Temperature for $\mathrm{xk} 2^{\mathrm{a}}$ & $15,15,13$ \\
\hline te 3 & Temperature for $x k 3^{a}$ & $17,17,15$ \\
\hline te 4 & Temperature for $\mathrm{xk}^{\mathrm{a}}$ & $23,25,23$ \\
\hline $\mathrm{xk} 1$ & Proportion of $C_{\mathrm{yu}}$ at te 1 & 0.10 \\
\hline $\mathrm{xk} 2$ & Proportion of $C_{\mathrm{MAX}}^{\mathrm{MA}}$ at te 2 & 0.98 \\
\hline $\mathrm{xk} 3$ & Proportion of $C_{\mathrm{MAX}}$ at te 3 & 0.98 \\
\hline $\mathrm{xk} 4$ & Proportion of $C_{\mathrm{MAX}}^{\mathrm{MAX}}$ at te 4 & 0.01 \\
\hline$v_{11}$ & Vulnerability of prey group 1 to predator 1 & $1.0,0.5,0.0$ \\
\hline$v_{12}$ & Vulnerability of prey group 2 to predator 1 & $0.1,1.0,0.5$ \\
\hline$v_{12}^{12}$ & Vulnerability of prey group 3 to predator 1 & $0.0,0.5,1.0$ \\
\hline$K_{11}^{13}$ & Half-saturation point for small zooplankton ${ }^{\mathrm{b}}$ & $0.4,0.85,0.78$ \\
\hline$K_{12}^{11}$ & Half-saturation point for large zooplankton ${ }^{\mathrm{b}}$ & $0.4,0.85,0.78$ \\
\hline$K_{13}^{12}$ & Half-saturation point for predatory zooplankton ${ }^{\mathrm{b}}$ & $0.4,0.85,0.78$ \\
\hline \multicolumn{3}{|c|}{ Metabolism } \\
\hline$a_{R}$ & Intercept for respiration & $0.0058,0.0033,0.0033$ \\
\hline$b_{R}^{R}$ & Weight exponent for respiration & $-0.007,-0.227,-0.227$ \\
\hline$c_{R}^{n}$ & Temperature effect for respiration & $0.083,0.0548,0.0548$ \\
\hline$d_{R}^{K}$ & Coefficient for swimming speed & $0.0,0.03,0.03$ \\
\hline \multicolumn{3}{|c|}{ Specific dynamic action } \\
\hline$a_{\mathrm{S}}$ & Coefficient for specific dynamic action & $0.125,0.15,0.175$ \\
\hline$a_{\mathrm{A}}$ & Intercept for swimming speed & $3.9,15.0$ \\
\hline$b_{A}^{A}$ & Weight exponent for swimming speed & 0.13 \\
\hline$c_{A}^{A}$ & Temperature effect for swimming speed & $0.149,0.0$ \\
\hline \multicolumn{3}{|c|}{ Egestion and excretion } \\
\hline$a_{F}$ & Proportion of consumed food egested & $0.125,0.16,0.16$ \\
\hline$a_{E}^{r}$ & Proportion of assimilated food excreted & $0.078,0.10,0.10$ \\
\hline
\end{tabular}

Population dynamics. - The numbers of individuals in each of the 10 age-classes were updated daily based on specified natural and fishing mortality rates. We used instantaneous rates of $0.44 /$ year for natural mortality (Schweigert and Tanasichuk 1999; Tanasichuk 2000) and 0.25/year for fishing mortality for age3 and older individuals (Stocker 1993; Ware and Schweigert 2002).

The initial number of age-1 individuals in each year was predicted from a spawner-recruit relationship developed by Williams and Quinn (2000b) for the WCVI Pacific herring stock. Williams and Quinn (2000b) incorporated three environmental variables into a Ricker stock-recruit model as follows:

$\frac{R}{\mathrm{SSB}}=\exp ^{3.27-0.031 \cdot \mathrm{SSB}+0.258 \cdot \mathrm{NPPI}-0.193 \cdot \mathrm{AIRT}-0.281 \cdot \mathrm{SST}}$,

where SSB is spawning stock biomass (thousands of metric tons), $R$ is recruitment to age 3 (millions), NPPI is the North Pacific pressure index, AIRT is the air temperature at Estevan Point, British Columbia $\left(49^{\circ} 22^{\prime} \mathrm{N}\right.$ and $\left.126^{\circ} 33^{\prime} \mathrm{W}\right)$, and SST is sea surface temperature within a box defined as $\pm 1^{\circ}$ of $53^{\circ} \mathrm{N}$ and $131^{\circ} \mathrm{W}$. The values for NPPI, AIRT, and SST were monthly values that were each first averaged to obtain single values per year (January through April for NPPI and SST; September through December for AIRT) and then expressed as annual anomalies $\left[\left(Y_{i}-\bar{Y}\right) / \sigma\right]$. The annual anomalies are computed for the same year that SSB is computed for (i.e., 3 years before recruitment).

For each year in the model, we computed the biomass of the spawning population on March 20 and used equation (3) to generate the number of age-3 recruits, which we then adjusted to obtain the number of age- 1 individuals entering the modeled population as age- 0 fish on June 20 of the same year as spawning. We specified the fraction of the population mature by age as 0.0 for age 1 and age 2, 0.95 for age 3, and 1.0 for age 4 and older (Hay and McCarter 1999). On March 15 of each year, we computed the SSB in grams of wet weight per cubic meter. We then multiplied this 


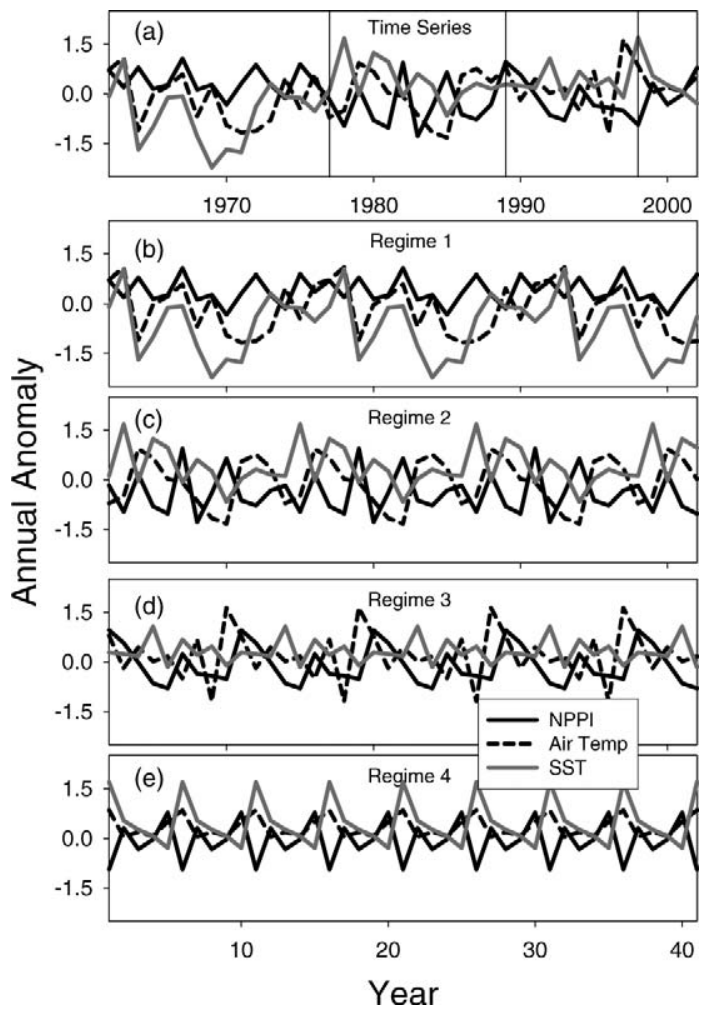

Figure 3.-Annual anomalies in three variables used in the spawner-recruit relationship-the North Pacific pressure index (NPPI), air temperature, and sea surface temperature (SST) - over (a) the historical time series and (b)-(d) regimes $1-4$.

SSB by the assumed volume of the summer feeding area inhabited by the southern British Columbia Pacific herring (the average depth of $100 \mathrm{~m} \times$ the occupied shelf area, estimated as $21,334 \mathrm{~km}^{2}$ ) to obtain SSB in thousands of metric tons. We assumed that half of the SSB went to WCVI to spawn and the other half went to SOG to spawn. During the period 1950-1990, the ratio of WCVI SSB to SOG SSB averaged 1.02 and the ratio of WCVI recruitment to SOG recruitment averaged 0.87 (Schweigert 2004). Using the computed SSB for WCVI and historical values for the NPPI, AIRT, and SST anomalies, we obtained $R / \mathrm{SSB}$ from equation (3). We then obtained the number of age- 1 recruits entering the model on June 20 of the same year as spawning by multiplying $R /$ SSB by the WCVI SSB in grams of wet weight per cubic meter, adjusting the number of age- 3 recruits by a calibrated constant to get the number of age- 1 recruits and then doubling the number of recruits to account for the half of the SSB that went to SOG.

We recognize two major assumptions underlying our use of the spawner-recruit relationship. First, while we used NPPI and SST environmental variables for the third of the year that overlapped spawning and recruitment, we used September through December for AIRT, even though recruitment has already occurred in June. Our rationale was that inclusion of AIRT was needed for accurate prediction of recruitment to age 3, which we then backed up to recruitment in June of the year of spawning. Second, our use of a simple multiplier to go from recruitment to age 3 to recruitment in June of the year of spawning can be questioned. Implicit in this adjustment is that all density dependence inherent in the spawner-recruit relationship predicted between spawning and age 3 would have occurred early in the first year. While this assumption is reasonable for our demonstration purposes, subsequent applications of our modeling approach should investigate more sophisticated adjustments of recruitment that reflect density dependence occurring after age-0 recruitment in June.

For this paper, we updated the three environmental variables of NPPI, SST, and AIRT used in the Williams and Quinn (2000b) spawner-recruit relationship (Figure 3a). We extended all three variables through 2002 and trimmed them at 1962 to obtain a consistent set of values that spanned all four of our regime periods. We then recomputed the annual anomalies based on the period 1962-2002 and checked that the spawner-recruit model, originally fit by Williams and Quinn (2000b) to 1948-1990 data, still provided a good fit to the historical SSB and recruitment data. Our new updated anomalies, when used with the original Williams and Quinn spawnerrecruit model, resulted in predicted annual recruitments for 1962 through 1990 that were very similar to the recruitments predicted using the original environmental time series and spawner-recruit model $\left(R^{2}=0.97\right)$.

Calibration of the Pacific herring component.Megrey et al. (2007) calibrated the Pacific herring component of the coupled models by varying the halfsaturation coefficients in the functional response $(K$; Table 1) and the scaling factor between age- 3 and age0 recruitment. They did not change the parameter values of the NEMURO model from the calibrated values determined by Rose et al. (2007) for WCVI. Simulated weights at age were averaged over a baseline simulation that closely corresponded to regime 3 conditions in this paper. Weight at age was the weight on March 10 just before spawning; thus, age-1 individuals were almost 12 months old, age- 2 individuals were just about 24 months old, and so on with subsequent ages. Megrey et al. (in press) adjusted the $K$ values and the scaling factor until simulated mean weights at age and adult summer biomass roughly agreed with the long-term average values for the 
TABLE 2.-Environmental conditions used for the spawner-recruit relationship (North Pacific pressure index, air temperature, and sea surface temperature) and the NEMURO lower trophic level (LTL) model (water temperature, mixed-layer depth, and nutrient influxing) in the historical time series, isolated-regime, recruitment-effect, LTL-effect, and no-regime-effect simulations.

\begin{tabular}{|c|c|c|c|}
\hline Simulation & $\begin{array}{l}\text { Number of } \\
\text { simulations }\end{array}$ & Spawner-recruit & NEMURO LTL \\
\hline Historical time series & 1 & $\begin{array}{l}\text { Used anomalies of the four regimes as } \\
\text { they occurred in their } 41 \text {-year temporal } \\
\text { sequence }\end{array}$ & $\begin{array}{l}\text { Used daily values generated by the four regime-specific } \\
\text { functions as they occurred in their } 41 \text {-year temporal } \\
\text { sequence }\end{array}$ \\
\hline Isolated regime effect & 4 & $\begin{array}{l}\text { Used anomalies for each regime } \\
\text { separately, each extended to } 41 \text { years }\end{array}$ & $\begin{array}{l}\text { Repeated a single year of daily values for } 41 \text { years, } \\
\text { corresponding to the functions fitted to each regime } \\
\text { separately }\end{array}$ \\
\hline Recruitment effect & 4 & $\begin{array}{l}\text { Used anomalies for each regime } \\
\text { separately, each extended to } 41 \text { years }\end{array}$ & $\begin{array}{l}\text { Repeated a single year of daily values obtained by } \\
\text { averaging the values generated from the four regime- } \\
\text { specific functions }\end{array}$ \\
\hline LTL effect & 4 & Set all anomalies to zero & $\begin{array}{l}\text { Repeated a single year of daily values for } 41 \text { years, } \\
\text { corresponding to the functions fitted to each regime } \\
\text { separately }\end{array}$ \\
\hline No regime effect & 1 & Set all anomalies to zero & $\begin{array}{l}\text { Repeated a single year of daily values obtained by } \\
\text { averaging the values generated from the four regime- } \\
\text { specific functions }\end{array}$ \\
\hline
\end{tabular}

southern British Columbia herring. We use the calibrated $K$ values and scaling factor determined by Megrey et al. (2007) for simulations in this paper.

\section{Model Simulations}

Five types of model simulations were performed to isolate the effects of the four climate regimes on Pacific herring growth and weights at age (Table 2). All simulations were for 41 years and used the coupled NEMURO and herring bioenergetics models, as calibrated for WCVI (Rose et al. 2007) and southern British Columbia herring (Megrey et al. 2007). We assumed that the calibrated versions of both models were representative of regime 3 because that was the time period for most of the data used to configure and calibrate the NEMURO model. We first performed a historical time-series simulation that used the regime information in temporal sequence. We then simulated each regime separately by repeating environmental conditions specific to each regime period. To determine the relative contribution of recruitment versus LTL effects on predicted weights at age, we simulated each regime period with one or both of these effects eliminated.

\section{Environmental Variables}

We specified the environmental anomalies, daily water temperature, mixed-layer depth, and nutrient influx rate into the modeled box to roughly mimic the conditions of each of the four regime periods (Table 3). Environmental anomalies used for the spawner-recruit model corresponded to years encompassed by the four regimes (Figure 3). We repeated the anomalies for the years within regimes until we obtained 41 years of anomalies for each regime. The function used to generate daily water temperatures for the NEMURO model and for the herring bioenergetics model was estimated separately based on temperatures divided into each of the four regime periods (Figure 2b).

We used the Bakun upwelling index (BUI; expressed as $\mathrm{m}^{3} / \mathrm{s}$ per $100 \mathrm{~m}$ of coastline) reported for $48^{\circ} \mathrm{N}$ and $125^{\circ} \mathrm{W}$ to help estimate regime-specific mixed-layer depths and nutrient influxing rates. Larger values of the BUI indicate greater upwelling. We first computed a BUI index value for each year by averaging monthly BUI values for the upwelling period of April through September, then we averaged the yearly values for each regime period (Table 3 ).

The environmental conditions (anomalies for recruitment and water temperature for NEMURO) used in simulations were generally consistent with the conditions described for the regimes (Table 3). Regime 1 had the highest NPPI value and the coolest air, sea surface, and NEMURO water temperatures; regime 3 had the second lowest NPPI value, the lowest BUI, and among the warmest temperatures. Regime 2 had a mix of high and low values for the temperature and upwelling indices.

The mixed-layer depth was made shallower during regimes 1, 2, and 4 than in regime 3 (Figure 2c; Table $3)$. The values used for mixed-layer depth in model simulations were loosely based on (albeit spotty) reported historical changes in mixed-layer depth near WCVI $\left(48^{\circ} \mathrm{N}\right.$ and $125^{\circ} \mathrm{W}$; NOAA Pacific Fisheries Environmental Laboratory, Pacific Grove, California). We computed an average mixed-layer depth for each year by averaging monthly mixed-layer depth values for whatever values were available for April through September, and then averaged the yearly values by regime for regimes 1, 2, and 3. No mixed-layer depth 
TABLE 3.-Values of the environmental variables used in the spawner-recruit and NEMURO lower trophic level (LTL) model simulations of the four regimes. The North Pacific pressure index (NPPI), air temperature (AIRT), and sea surface temperature (SST) are averages of the annual anomalies. Daily water temperature $\left({ }^{\circ} \mathrm{C}\right)$ is the average of June, July, and August values; the mixed-layer depth (MLD) is the depth (m) during the April 9-September 6 period; nutrient influxing is the multiplier (exchange rate) that determines the flux of nitrate into the modeled box from below during the upwelling period. The Bakun upwelling index (BUI) was used in the estimation of the mixed-layer depth for regime 4 as well as in the estimation of the nutrient influxing multipliers. The BUI is the average of April-September monthly values; mean annual values are shown in the table.

\begin{tabular}{crrrrrrrrr}
\hline & \multicolumn{3}{c}{ Spawner-recruit } & & \multicolumn{4}{c}{ NEMURO LTL } & \\
\cline { 2 - 3 } Regime & NPPI & AIRT & SST & & Water temperature & MLD & Nutrient influxing multiplier & BUI \\
\hline \multirow{2}{*}{1} & 0.39 & -0.16 & -0.65 & & 12.4 & 26 & 8.2 & 22.7 \\
2 & -0.39 & -0.10 & 0.38 & & 13.0 & 23 & 10.4 & 25.4 \\
3 & -0.11 & 0.21 & 0.32 & & 13.2 & 30 & 5.0 & 16.0 \\
4 & -0.04 & 0.33 & 0.45 & & 12.4 & 28 & 6.8 & 20.3 \\
\hline
\end{tabular}

values were reported for regime 4 . We then adjusted the observed mixed-layer depths for regime 1,2, and 3 so that the observed mixed-layer depth in regime 3 matched the $30 \mathrm{~m}$ depth assumed in the model. This results in mixed-layer depths of $26 \mathrm{~m}$ in regime 1 and 23 $\mathrm{m}$ in regime 2 . Because the average mixed-layer depths were related to the average BUI across regimes 1, 2, and 3 , we used the BUI for regime 4 to determine a mixedlayer depth of $28 \mathrm{~m}$ for regime 4 (Figure 2c; Table 3).

The values for mixed-layer depth and the BUI were used to specify nutrient influxing rates for regimes 1, 2, and 4 (Table 3). Robinson et al. (1993) assumed that the influx of nutrients was proportional to the BUI and inversely proportional to the mixed-layer depth. Assuming that the average mixed-layer depth and BUI for regime 3 corresponded to five times the nutrient influxing value (Rose et al. 2007), we used the mixed-layer depths and average values of the BUI to adjust the $5 \times$ multiplier assumed in regime 3 to influxing values for the other regimes $(8.2 \times$ in regime $1,10.4 \times$ in regime 2 , and $6.8 \times$ in regime 4 ; Table 3 ).

\section{Historical Time Series Simulation}

We first preformed a 41-year historical time series simulation with the four regime periods in temporal sequence (Table 2). We used the historical annual environmental anomalies (Figure 3a), and the water temperature, mixed-layer depth, and nutrient influxing at their regime-specific values for all of the years within each regime period (Figure $2 b, c)$. We show predicted monthly nitrate, total phytoplankton, and zooplankton concentrations for a representative year within each regime. For Pacific herring, we show predicted annual values of SSB, recruitment, and mean weight at age for age 4 through 10. Recruitment and SSB were the values computed for the WCVI spawning component. We also compared the observed data of weight at age 4, recruitment, and SSB by regime period shown in Figure 1 with predicted values from the historical time series simulation. Each point in the box plots corresponded to a year within that regime period. Based on our model assumption that one-half of the spawners go to WCVI, the SSB and recruitment values for the southern British Columbia group would be twice the values we show. Mean weight at age and SSB were computed just before spawning (i.e., on their birthdays).

\section{Isolated Regime Effects Simulations}

The second type of simulation was the simulation of each of the four regimes separately for 41 years (Table 2). For each regime, we repeated the environmental anomalies of that period (Figure 3b-e), and repeated the annual set of daily values of water temperature, mixed-layer depth, and nutrient influxing specific to the regime. We show predicted annual values of SSB, recruitment, and mean weight at age for 4-year-old and 10 -year-old fish.

\section{Recruitment versus LTL Effects Simulations}

The third, fourth, and fifth types of simulations were designed to determine the relative contribution of recruitment versus LTL effects to the weight-at-age responses predicted under the isolated regime-effects simulations (Table 2). The recruitment effect was eliminated by specifying the NPPI, AIRT, and SST anomalies as zero. The LTL effect was eliminated by using daily water temperatures, mixed-layer depth, and nutrient influxing for NEMURO that were averaged, for each day of the year, over the values generated for the four regimes.

The third simulation type was the recruitment-effect simulations. For each regime, year-specific anomalies were used in the spawner-recruit relationship, while a single set of daily values (averaged over the four regimes) of water temperature, mixed-layer depth, and nutrient influxing values were used for the NEMURO model.

The fourth type of simulation was the LTL-effect 

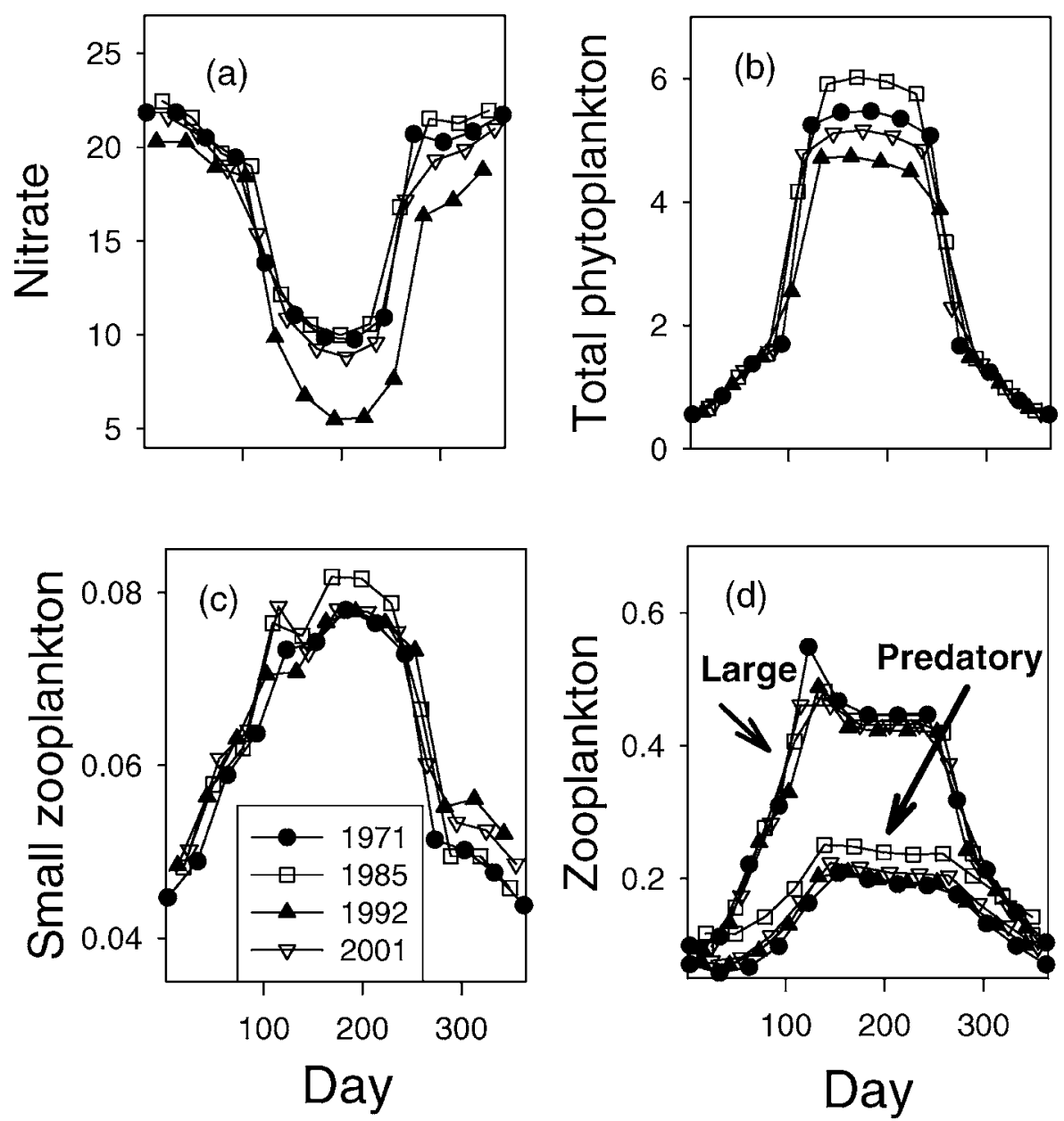

FIGURE 4.-Predictions from the coupled NEMURO nutrient-phytoplankton-zooplankton and bioenergetics models for Pacific herring in the historical time series simulation. Monthly predictions are shown for (a) nitrate, (b) total phytoplankton, (c) small zooplankton, and (d) large and predatory zooplankton for a representative year in each of the four regimes (1-4).

simulations. For each regime, regime-specific functions were used to generate daily values of water temperature, mixed-layer depth, and nutrient influxing, while all of the environmental anomalies used in the spawner-recruit relationship were set to zero.

The fifth type of simulation was the no-effect simulation. The no-effect simulation removed the influence of regime-specific conditions on recruitment and on the LTL dynamics. We performed a single simulation with environmental anomalies set at zero and averaged temperature, mixed-layer depth, and nutrient influxing. The same no-effect simulation was used as the basis of comparison for all four of the regime periods.

For each of the regimes, we compared the predicted average weights at age for 4-year-old and 10-year-old fish among the isolated regime-effect, recruitmenteffect, LTL-effect, and no-effect simulations.

\section{Results}

\section{Historical Time Series Simulation}

The historical time series simulation resulted in only small effects on the lower trophic levels (Figure 4a-d). Monthly nitrate concentrations during the summer were lowest in regime 3 (represented by 1992; Figure 4a), and total phytoplankton and small zooplankton concentrations were slightly higher in regime 2 (represented by 1985; Figure 4b, c). However, these differences, while consistent among regimes, were small in magnitude. Little differences in large and predatory zooplankton concentrations were predicted among the four regimes (Figure 4d). 

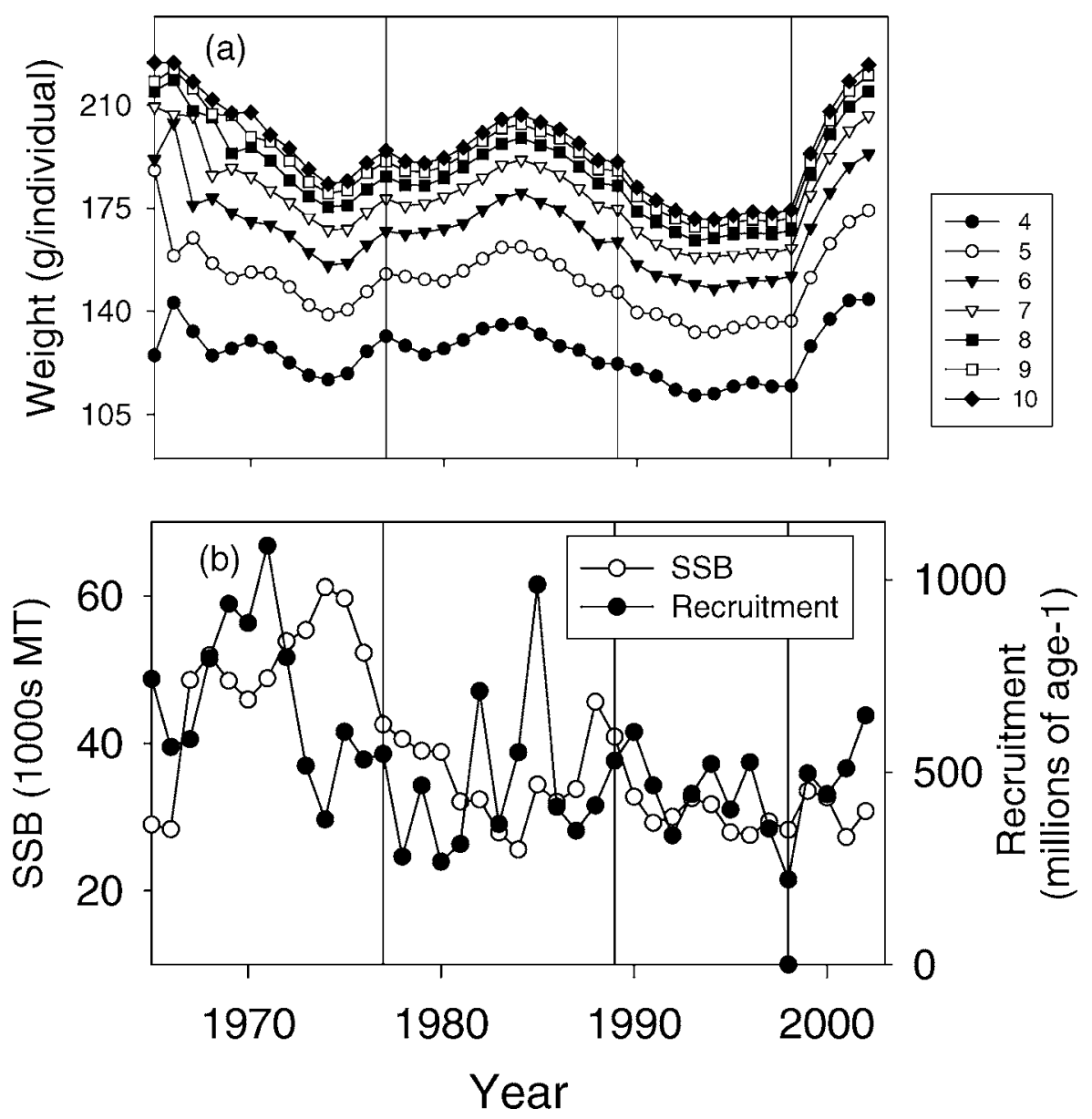

FIGURE 5.- Model predictions in the historical time series simulation for the (a) weight at ages 4-10 and (b) spawning stock biomass (SSB; MT = metric tons) and recruitment of Pacific herring. The vertical lines denote the four regimes studied.

The historical time series simulation generated clear responses in Pacific herring growth and resulted in a downward trend in SSB, recruitment, and mean weights at age, with perhaps some recovery of growth rates in regime 4 (Figure 5; Table 4). Regime 3 showed the slowest growth and had the lowest mean weights at age; growth rate was relatively fast in regimes 1,2 , and
4 (Figure 5a). The mean weight at age for 4-year-old fish was about $10 \%$ lower in regime $3(115.8 \mathrm{~g})$ than in the other regimes $(126.7,129.9$, and $133.6 \mathrm{~g}$, in regimes 1, 2, and 4, respectively; Table 4). Recruitment and SSB were highest in regime 1 and generally similar and low in the other three regimes (Figure 5b). Mean SSB was 44,200 metric tons in regime 1, compared

TABLE 4.-Average annual spawning stock biomass (SSB; thousands of metric tons), recruitment (millions of age-1 fish), and mean individual weights ( $\mathrm{g}$ ) at age 4 and at age 10 for each of the four regime periods in the historical time series (TS) simulation and the four isolated-regime (I) simulations. Recruitment and SSB are for the West Coast of Vancouver Island component of the southern British Columbia group.

\begin{tabular}{|c|c|c|c|c|c|c|c|c|}
\hline \multirow[b]{2}{*}{ Regime } & \multicolumn{2}{|c|}{ SSB } & \multicolumn{2}{|c|}{ Recruitment } & \multicolumn{2}{|c|}{ Age-4 weight } & \multicolumn{2}{|c|}{ Age-10 weight } \\
\hline & TS & I & TS & I & TS & I & TS & I \\
\hline 1 & 44.2 & 46.5 & 704.1 & 720.9 & 126.7 & 128.5 & 201.0 & 201.7 \\
\hline 2 & 35.4 & 32.5 & 471.7 & 460.7 & 129.9 & 129.5 & 197.5 & 198.9 \\
\hline 3 & 31.3 & 28.4 & 464.8 & 464.1 & 115.8 & 113.9 & 176.3 & 173.4 \\
\hline 4 & 30.5 & 33.6 & 463.7 & 454.7 & 133.6 & 137.8 & 203.5 & 221.3 \\
\hline
\end{tabular}


with 30,500-35,400 metric tons in regimes 2,3 , and 4 (Table 4). Mean recruitment was about 1.5 times higher in regime 1 than in the other regimes (704.1 million in regime 1 versus 463.7-471.7 million in regimes 2, 3, and 4; Table 4). With only a few years of data, it is difficult to interpret model predictions for regime 4 .

The predicted patterns in weight at age, SSB, and recruitment were generally consistent with observed values for regimes 1, 2, and 3 (Figure 6). We allowed predicted and observed values to be on different $y$-axis scales to emphasize their patterns among regimes, rather than similarities in their absolute values. Ignoring regime 4 , the predicted and observed mean weights at age $4, \mathrm{SSB}$, and recruitment were relatively low in regime 3 , and weight at age 4 and recruitment were relatively high in regime 1 .

\section{Isolated Regime Effects}

When we isolated the effects of each regime over the long term we saw patterns that were roughly similar to the historical time series simulation (Figure 7; Table 4). Regime 1 conditions resulted in the highest recruitment and SSB, and regime 3 conditions generated the lowest recruitment (similar to recruitment in regimes 2 and 4; Figure 7a), lowest SSB (Figure 7b), and slowest growth (Figure 7c, d). Average SSB, recruitment, and weight at age of 4-year-old fish were similar between the isolated regime simulation and the values predicted during the same regime in the historical time-series simulation (I versus TS columns in Table 2). For example, SSB (thousands of metric tons) for the isolated regime and historical time series simulations was 46.5 versus 44.2 for regime $1,32.5$ versus 35.4 for regime 2, 28.4 versus 31.3 for regime 3 , and 33.6 versus 30.5 for regime 4 . The one exception was for the mean weight at age for 10 -year-old fish for regime 4 , in which the isolated regime simulation resulted in a mean weight at age 10 of $221.3 \mathrm{~g}$, compared with the lower value of $203.5 \mathrm{~g}$ obtained during regime 4 in the historical time series simulation. The fast growth suggested in regime 4 became much more apparent in the isolated regime simulations; when regime conditions were repeated for 41 years, regime 4 generated the heaviest weights at age (Figure $7 \mathrm{c}, \mathrm{d}$ ).

The isolated regime simulations showed the densitydependent effects of Pacific herring feeding on their prey. The temporal cycle of SSB (Figure 7a) from the recycled use of the environmental anomalies, especially for regimes 1 and 2, was mirrored (inversely related) in the simulated weights at age (Figure 7c, d). Part of the fast growth predicted in regime 4 is due to the very short time series of environmental anomalies, which when used repeatedly generated low recruitment and low adult biomass that resulted in fast growth and

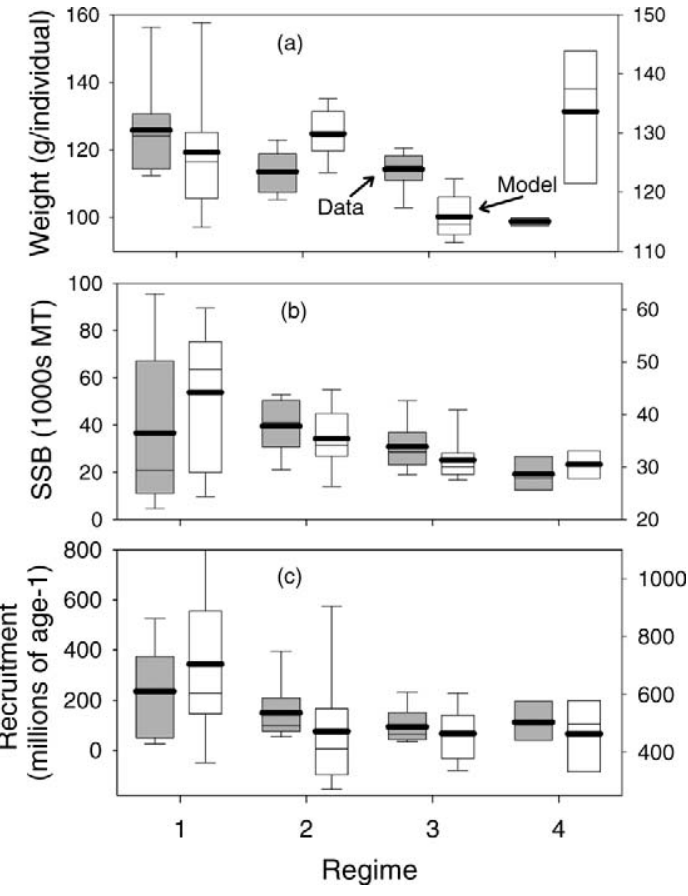

FIGURE 6.- Predicted (shaded boxes) and observed (unshaded boxes) annual (a) mean weight at age 4, (b) spawning stock biomass (SSB; MT = metric tons), and (c) recruitment of Pacific herring in the four regime periods. The box shows the 25th and 75th percentiles, and the whiskers show the 10th and 90th percentiles; the thin line is the median, and the thick line is the mean.

relatively small effects of herring on the zooplankton dynamics.

\section{Recruitment versus LTL Effects}

The regime effect on weight at age varied among the four regimes and was a combination of the recruitment response and the response via the LTL (Figure 8). The results for weight at age were consistent between 4year-old and 10-year-old fish (compare Figure 8a and $8 b)$. In regime 1 , the recruitment effect caused a decrease in mean weight at age, while the LTL effect caused an increase. The resulting regime-effect simulation was similar to the no-effect simulation because the recruitment and LTL effects essentially canceled each other. Both the recruitment and LTL effects were small for regime 2 . In regime 3 , the regime effect was dominated by the LTL effect, the recruitment effect causing a slight increase in mean weight at age and the LTL effect a large decrease. The recruitment and LTL effects both caused increases in mean weight at age in regime 4 , combining in an additive manner so that regime 4 generated the heaviest weights at age. 

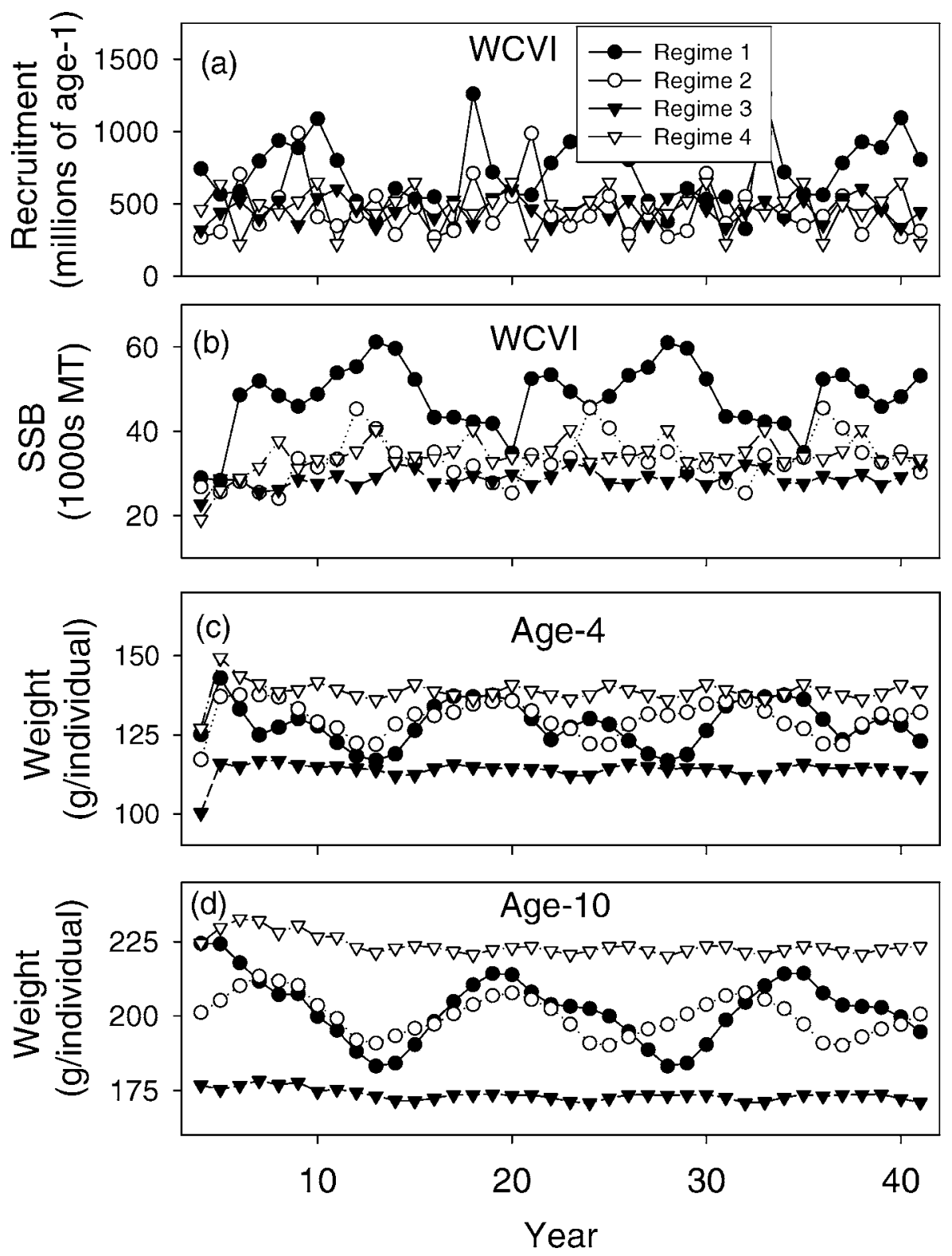

FIGURE 7.- Predictions of (a) recruitment at the west coast of Vancouver Island (WCVI), (b) spawning stock biomass (SSB; $\mathrm{MT}=$ metric tons) at WCVI, (c) weight at age 4, and (d) weight at age 10 for Pacific herring from the coupled NEMURO nutrient-phytoplankton-zooplankton and bioenergetics models in the four isolated regime simulations using the environmental conditions that prevailed in each regime period for the entire 41 years of the study.

\section{Regime Effects}

\section{Discussion}

Our model simulations showed that the four regimes would have different effects on the biomass and weight at age of Pacific herring at WCVI. Regime 1 conditions consistently resulted in the highest recruitment and $\mathrm{SSB}$, and the fastest or near-fastest growth (heaviest weights at age). Regime 3 conditions produced low recruitment (similar to regimes 2 and 4), the lowest biomass, and the slowest growth. Regimes 2 and 4 generated relatively low biomass, but when isolated they both resulted in relatively fast growth. Interestingly, the fastest growth and heaviest weights at age were predicted for regime 4 , which was the coolest 
regime. Regime 4 was not, however, the regime with the best conditions for LTL production; regimes 1 and 2 had shallower mixed-layer depths and higher nutrient influxing rates.

The degree to which our predicted differences in weights at age among the four regimes agree with the field data are subject to debate. Our predicted responses were qualitatively similar to the observations by others that regimes 1 and 2 were periods of fast growth and high recruitment and regime 3 was a period of slow growth and low recruitment for many fish species (Beamish et al. 2004; MacCall et al. 2005). Observed and predicted SSB, recruitment, and weights at age seemed to agree at least in pattern, with all generally high in regimes 1 and 2 and low in regime 3 (Figure 6). However, we also predicted fast Pacific herring growth for regime 4, which appears to be the opposite of what has been observed to date. However, our fast growth predicted for regime 4 occurred with low simulated SSB and recruitment, and therefore low simulated summer adult biomass, whereas field-derived summer biomasses have not declined due to increasing SSB and recruitment from the SOG stock (McFarlane et al. 2001). We acknowledge that the changes we imposed on model inputs among regimes were educated guesses, and we are always suspicious of the robustness of spawner-recruit relationships (Hilborn and Walters 1992).

\section{Two of Many Caveats}

Two major caveats inherent in our modeling analysis are (1) the assumption of fixed values for the vulnerability $(v)$ and half-saturation feeding $(K)$ coefficients and (2) the assumption of coherence between WCVI and SOG recruitment. As zooplankton concentrations vary within years and among regimes, the feeding and prey selection of Pacific herring are undoubtedly more flexible and plastic than is implied by the fixed values for $v$ and $K$ (see Dill 1983). Changes in herring feeding behavior and prey selection could affect our predicted differences in mean weight at age among the regimes.

A second major assumption underlying our analysis is that the SSB splits evenly between WCVI and SOG and that the resulting recruitment from SOG spawning follows the WCVI spawner-recruit relationship. Simulated herring biomass in the model was fit to observed summer biomass that reflected both WCVI- and SOGspawned fish because we wanted realistic summertime biomass in the simulations to allow for densitydependent growth effects. At the same time, we also wanted to be able to isolate the effect of regimes on the WCVI stock. We therefore assumed that recruitment from SOG spawning would be the same as recruitment
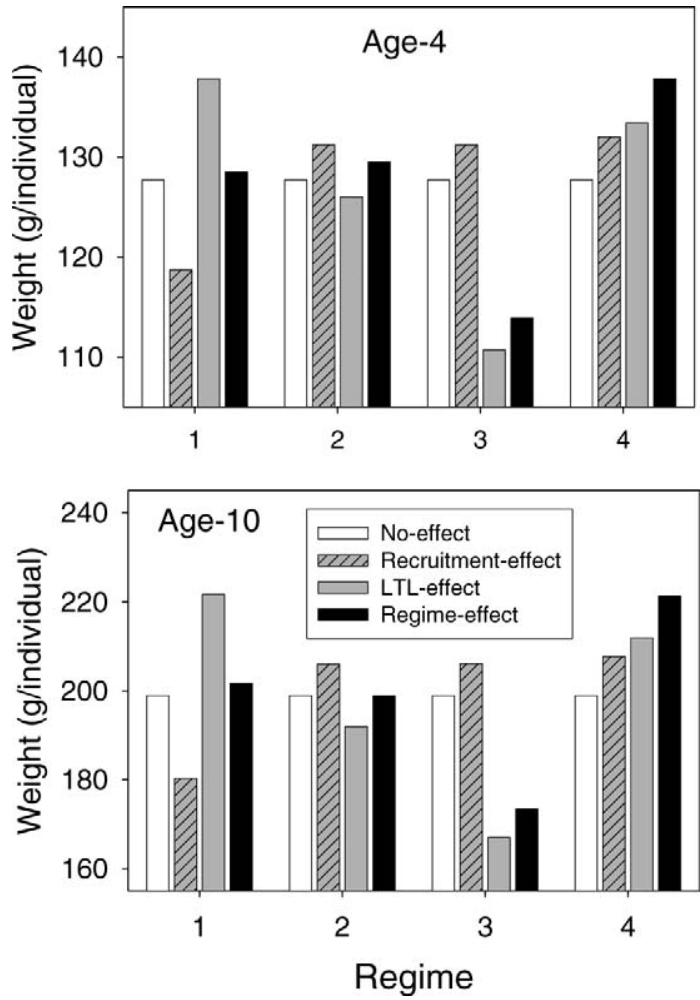

FIGURE 8.-Predicted mean weights for (a) age-4 and (b) age-10 Pacific herring in the no-effect, recruitment-effect, lower trophic level (LTL)-effect, and regime-effect simulations in each of the four regimes. See text for details.

from WCVI spawning. Williams and Quinn (2000a) determined that recruitment anomalies between 1948 and 1990 for the WCVI and SOG stocks were synchronous, and that the two stocks exhibited similar temporal variation in their recruitment. The best spawner-recruit model for the SOG stock had a similar dependence on spawning stock biomass and sea surface temperature as the WCVI spawner-recruit relationship (Williams and Quinn 2000b). However, since the 1990s the SSB and recruitment have not been synchronous between the two stocks (McFarlane et al. 2001).

\section{Future Modeling}

The present version of the coupled NEMURO and Pacific herring growth models could be improved by obtaining better estimates of the allometric parameters of the maximum consumption and respiration functions, further elaborating the reproduction-to-recruitment and mortality aspects of herring, and embedding the coupled models in a two-dimensional spatial grid. Megrey et al. (2007) used Monte Carlo uncertainty 
analysis and varied all model parameters, only NEMURO-related parameters, and only fish-related parameters under low and high herring biomass conditions. They concluded that weight at age 5 and summertime herring biomass were most sensitive to the allometric parameters of the maximum consumption and respiration functions, the growth efficiency of the large zooplankton group, and the maximum photosynthetic rate of the large phytoplankton group. Additional laboratory experiments on herring consumption and respiration, under different temperature conditions (including extremes) and for a range of herring sizes, would improve model simulations of herring growth.

Pacific herring reproduction and recruitment in the model could be expanded by further elaboration of the scaling factor that converts age-3 recruits generated from the spawner-recruit relationship to the age-0 recruits entering the modeled population. Alternative formulations of the scaling factor and modifications to the survival of age- 2 and age- 3 herring would allow for some or all of the density dependence inherent in the spawner-recruit relationship to be put beyond the age- 0 period, as assumed in the present formulation. Norcross and Brown (2001) and Stokesbury et al. (2002) recently estimated natural mortality rates for age-0 herring.

The constant mortality rates of Pacific herring in the model could be made more realistic by considering some of the key food web interactions. Analysis of long-term data suggests that natural mortality rates of southern British Columbia herring populations increase with age, and that total survival can vary greatly from year to year (Tanasichuk 2000). Robinson and Ware (1994, 1999) developed a one-box difference equation model configured for the food web of WCVI. Their model used weekly values of sea surface temperature, solar radiation, and BUI as driving variables and simulated the daily biomasses of diatoms, copepods, euphausiids, herring, hake, Chinook salmon Oncorhynchus tshawytscha, and spiny dogfish Squalus acanthias over a 1-year period. Simulations of 19851995 conditions showed that herring biomass depended on the interaction between hake predation on herring and the dynamics of their shared prey (euphasiids).

The types of scenarios we could investigate would be broadened by imbedding our coupled models into a two-dimensional spatial grid. Using a single spatial box to represent a coastal upwelling ecosystem severely limits the generality of our model because we must force changes in upwelling dynamics via inferred or guessed changes in aggregated model inputs. Some readers may conclude that our use of a single box for an upwelling system poses unreasonable limits. An explicit two-dimensional spatial approach would allow us to change the environmental forcing and the let the physics predict the changes in upwelling and LTL responses. Conceptually, there is nothing to prevent us from imbedding our point model into a two-dimensional spatial grid that simulates advection and dispersion. Wainwright et al. (2007) used a slightly modified version of NEMURO within a two-dimensional spatial grid to simulate the California Current upwelling system. If we used the same approach we could further resolve our age-classes into individual herring and use a Lagrangian approach to simulate spatially explicit feeding and movement (Tyler and Rose 1994). We view the analyses presented in this paper as a first step toward a more spatially explicit approach.

\section{Concluding Remark}

The synchrony of recruitment, abundance, and growth across production domains implies that at least some of the aspects of the population dynamics of affected fish are due to regime effects and not to fishing. Regime conditions and expected future regime shifts should be combined with life history considerations (e.g., longevity, fecundity, and maturity) and incorporated into fisheries stock assessments and management advice (King et al. 2005). Understanding how regimes affect populations is critical to ensuring that we attribute the appropriate population dynamics to fishing and would allow us to adjust harvest for favorable and unfavorable climatic conditions (Beamish et al. 2000, 2004). We acknowledge that our analysis is overly simplified, but it represents a first step toward coupling NPZ and fish bioenergetics models in order to quantify the linkage between climate and fish population dynamics.

\section{Acknowledgments}

We thank the Asia Pacific Network (APN), North Pacific Marine Science Organization, Heiwa-Nakajima Foundation of Japan, Japan International Science and Technology Exchange Center, city of Nemuro (Japan), and Fisheries Research Agency of Japan for sponsoring a series of workshops that resulted in the development of the NEMURO model and its coupling to fish growth dynamics. We especially recognize the vital roles played by M. J. Kishi (Hokkaido University), Y. Yamanaka (Frontier Research Center for Global Change), and S. Ito (Tohoku National Fisheries Research Institute) in organizing the workshops and their contributions to the development of the NEMURO model and code. The regime analyses in this paper was the result of an APN-funded workshop entitled "Climate Interactions and Marine Ecosystems" held 10-13 October 2004 in Honolulu, Hawaii. 
B.A.M.'s participation in this research is noted as contribution FOCI-0544 to NOAA's Fisheries-Oceanography Coordinated Investigations.

\section{References}

Arrhenius, F. 1998. Variable length of daily feeding period in bioenergetics modelling: a test with 0-group Baltic herring. Journal of Fish Biology 52:855-860.

Arrhenius, F., and S. Hansson. 1994. In situ food consumption by young-of-the-year Baltic Sea herring Clupea harengus: a test of predictions from a bioenergetics model. Marine Ecology Progress Series 110:145-149.

Batten, S. D., and D. W. Welch. 2004. Changes in oceanic zooplankton populations in the northeast Pacific associated with the possible climatic regime shift of 19981999. Deep-Sea Research, Part II 51:863-873.

Beamish, R. J., editor. 1995. Climate change and northern fish populations. Canadian Special Publication of Fisheries and Aquatic Sciences 121.

Beamish, R. J., A. J. Benson, R. M. Sweeting, and C. M. Neville. 2004. Regimes and the history of the major fisheries off Canada's West Coast. Progress in Oceanography 60:355-385.

Beamish, R. J., G. A. McFarlane, and J. R. King. 2000. Fisheries climatology: understanding decadal scale processes that naturally regulate British Columbia fish populations. Pages 94-139 in P. Harrison and T. Parsons, editors. Fisheries oceanography: an integrative approach to fisheries ecology and management. Blackwell Scientific Publications, Malden, Massachusetts.

Benaka, L. R., editor. 1999. Fish habitat: essential fish habitat and rehabilitation. American Fisheries Society, Symposium 22, Bethesda, Maryland.

Benson, A. J., and A. W. Trites. 2002. Ecological effects of regime shifts in the Bering Sea and eastern North Pacific Ocean. Fish and Fisheries 3:95-113.

Beyers, D. W., J. A. Rice, and W. H. Clements. 1999. Evaluating biological significance of chemical exposure to fish using a bioenergetics-based stressor-response model. Canadian Journal of Fisheries and Aquatic Sciences 56:823-829.

Bograd, S. J., P. M. DiGiacomo, R. Durazo, T. L. Hayward, K. D. Hyrenbach, R. J. Flynn, A. W. Mantlya, F. B. Schwing, W. J. Sydeman, T. Baumgartner, B. Lavaniegos, and C. S. Moore. 2000. The state of the California Current, 1999-2000: forward to a new regime? California Cooperative Oceanic Fisheries Investigations Reports 41:26-52.

Brinton, E., and A. Townsend. 2003. Decadal variability in abundances of the dominant euphausiid species in southern sectors of the California Current. Deep-Sea Research, Part II 50:2449-2472.

Cooke, S. J., C. M. Blunt, J. F. Schreer, and D. H. Wahl. 2001. Comparison of several techniques for mobility and activity estimates of smallmouth bass in lentic environments. Journal of Fish Biology 58:573-587.

Dill, L. M. 1983. Adaptive flexibility in the foraging behavior of fishes. Canadian Journal of Fisheries and Aquatic Sciences 40:398-408.

Francis, R. C., S. R. Hare, A. B. Hollowed, and W. S. Wooster. 1998. Effects of interdecadal climate variability on the ocean ecosystems of the NE Pacific. Fisheries Oceanography 7:1-21.

Gottlieb, S. J. 1998. Nutrient removal by age-0 Atlantic menhaden (Brevoortia tyrannus) in Chesapeake Bay and implications for seasonal management of the fishery. Ecological Modelling 112:111-130.

Hansen, M. J., D. Boisclair, S. B. Brandt, S. W. Hewett, J. F. Kitchell, M. C. Lucas, and J. J. Ney. 1993. Applications of bioenergetics models to fish ecology and management: where do we go from here? Transactions of the American Fisheries Society 122:1019-1030.

Hanson, P. C., T. B. Johnson, D. E. Schindler, and J. F. Kitchell. 1997. Fish Bioenergetics 3.0. University of Wisconsin Sea Grant Institute, WISCU-T-97-001, Madison.

Hartman, K. J., and S. B. Brandt. 1995. Trophic resource partitioning, diets, and growth of sympatric estuarine predators. Transactions of the American Fisheries Society 124:520-537.

Harvey, C. J. 2005. Effects of El Nino events on energy demand and egg production of rockfish (Scorpaenidae: Sebastes): a bioenergetics approach. U.S. National Marine Fisheries Service Fishery Bulletin 103:71-83.

Hay, D. E., J. R. Brett, E. Bilinski, D. T. Smith, E. M. Donaldson, G. A. Hunter, and A. V. Solmie. 1988. Experimental impoundments of prespawning Pacific herring (Clupea harengus pallasi): effects of feeding and density on maturation, growth, and proximate analysis. Canadian Journal of Fisheries and Aquatic Sciences 45:388-398.

Hay, D. E., and P. B. McCarter. 1999. Age of sexual maturation and recruitment in Pacific herring. Canadian Science Advisory Secretariat, Research Document 99/ 175, Ottawa. Available: www.dfo-mpo.gc.ca/csas/. (June 2005).

Hay, D. E., R. Toresen, R. Stephenson, M. Thompson, R. Claytor, F. Funk, E. Ivshina, J. Jakobsson, and T. Kobayashi. 2001. Taking stock: an inventory and review of world herring stocks in 2000. Pages 381-454 in F. Funk, J. Blackburn, D. Hay, A. J. Paul, R. Stephenson, R. Toresen, and D. Witherell, editors. Herring: expectations for a new millennium. University of Alaska, Sea Grant, AK-SG-01-04, Fairbanks.

Hilborn, R., and C. J. Walters. 1992. Quantitative fisheries stock assessment: choice, dynamics, and uncertainty. Chapman and Hall, New York.

Hollowed, A. B., and W. S. Wooster. 1992. Variability of winter ocean conditions and strong year-classes of Northeast Pacific groundfish. ICES Marine Science Symposia 195:433-444.

Hollowed, A. B., and W. S. Wooster. 1995. Decadal-scale variations in the eastern subarctic Pacific, II. Responses of Northeast Pacific fish stocks. Pages 373-385 in R. J. Beamish, editor. Climate change and northern fish populations. Canadian Special Publication of Fisheries and Aquatic Sciences 121.

Hondorp, D., and S. B. Brandt. 1996. Spatially explicit models of fish growth rate: tools for assessing habitat quality. Great Lakes Research Review 2:11-19.

Hurrell, J. W., and H. van Loon. 1997. Decadal variations in climate associated with the North Atlantic Oscillation. Climatic Change 36:301-326. 
Johnson, B. L. 1992. Transfer of computer software technology through workshops: the case of fish bioenergetics modeling. Fisheries 17(6):14-18.

Kawasaki, T. 1992. Climate-dependent fluctuations in the Far Eastern sardine population and their impacts on fisheries and society. Pages 325-354 in M. H. Glantz, editor. Climate variability, climate change, and fisheries. Cambridge University Press, Cambridge, UK.

King, J. R., editor. 2005. Report of the study group on the fisheries and ecosystem responses to recent regime shifts. North Pacific Marine Science Organization (PICES), PICES Scientific Report 28, Sidney, British Columbia.

King, J. R., G. A. McFarlane, A. B. Hallowed, A. D. MacCall, and J. J. Poloniva. 2005. Implications for the management of marine resources. Pages 51-54 in J. R. King, editor. Report of the study group on the fisheries and ecosystem responses to recent regime shifts. North Pacific Marine Science Organization (PICES), PICES Scientific Report 28, Sidney, British Columbia.

Kishi, M. J., D. L. Eslinger, M. Kashiwai, B. A. Megrey, D. M. Ware, F. E. Werner, M. Aita-Noguchi, T. Azumaya, M. Fujii, S. Hashimoto, H. Iizumi, Y. Ishida, S. Kang, G. A. Kantakov, H.-C. Kim, K. Komatsu, V. V. Navrotsky, L. S. Smith, K. Tdokoro, A. Tsuda, O. Yamamura, Y. Yamanaka, K. Yokouchi, N. Yoshie, J. Zhang, Y. I. Zuenko, and V. I. Zvansky. 2007. NEMURO: Introduction to a lower trophic level model for the North Pacific marine ecosystem. Ecological Modelling 202:12-25.

Klumb, R. A. 2002. Review of clupeid biology with emphasis on energetics. Pages 88-93 in H. P. Batchelder, G. A. McFarlane, B. A. Megrey, D. L. Mackas, and W. T. Peterson, editors. Report of 2001 bass/model, monitor and rex workshops, and the 2002 model/rex workshop. North Pacific Marine Science Organization (PICES), Sidney, British Columbia.

Lassuy, D. R. 1989. Species profiles: life histories and environmental requirements of coastal fishes and invertebrates (Pacific Northwest): Pacific herring. U.S. Fish and Wildlife Service Biological Report 82(11.126), Washington, D.C. and U.S. Army Corps of Engineers, TR-EL-82-4, Vicksburg, Mississippi.

MacCall, A. D., H. Batchelder, J. King, D. Mackas, N. Mantua, G. A. McFarlane, I. Perry, J. F. Schweigert, and F. Schwing. 2005. Recent ecosystem changes in the California Current system. Pages 65-86 in J. R. King, editor. Report of the study group on the fisheries and ecosystem responses to recent regime shifts. North Pacific Marine Science Organization (PICES), PICES Scientific Report 28, Sidney, British Columbia.

Mackas, D. L., W. T. Peterson, and J. E. Zamon. 2004. Comparisons of interannual biomass anomalies of zooplankton communities along the continental margins of British Columbia and Oregon. Deep-Sea Research, Part II 51:875-896.

Maes, J., K. E. Limburg, A. van de Putte, and F. Ollevier. 2005. A spatially explicit, individual-based model to assess the role of estuarine nurseries in the early life history of North Sea herring, Clupea harengus. Fisheries Oceanography 14:17-31.

McDermot, D., and K. A. Rose. 1999. An individual-based model of lake fish communities: application to piscivore stocking in Lake Mendota. Ecological Modelling 125:67-102.

McFarlane, G. A., R. J. Beamish, and J. Schweigert. 2001. Common factors have opposite impacts on Pacific herring in adjacent ecosystems. Pages 51-67 in F. Funk, J. Blackburn, D. Hay, A. J. Paul, R. Stephenson, R. Toresen, and D. Witherell, editors. Herring: expectations for a new millennium. University of Alaska, Sea Grant, AK-SG-01-04, Fairbanks.

Megrey, B. A., K. A. Rose, R. Klumb, D. Hay, F. E. Werner, and L. Smith. 2007. A bioenergetics population dynamics model of Pacific herring (Clupea pallasii) coupled to NEMURO: dynamics, description, validation, and sensitivity analysis. Ecological Modelling 202:144-164.

Miller, A. J., and N. Schneider. 2000. Interdecadal climate regime dynamics in the North Pacific Ocean: theories, observations, and ecosystem impacts. Progress in Oceanography 47:355-379.

Ney, J. J. 1990. Trophic economics in fisheries: assessment of demand-supply relationships between predators and prey. Reviews in Aquatic Sciences 2:55-81.

Ney, J. J. 1993. Bioenergetics modeling today: growing pains on the cutting edge. Transactions of the American Fisheries Society 122:736-748.

Norcross, B. L., and E. D. Brown. 2001. Estimation of firstyear survival of Pacific herring from a review of recent stage-specific studies. Pages 535-558 in F. Funk, J. Blackburn, D. Hay, A. J. Paul, R. Stephenson, R. Toresen, and D. Witherell, editors. Herring: expectations for a new millennium. University of Alaska, Sea Grant, AK-SG-01-04, Fairbanks.

Pauly, D., V. Christensen, J. Dalsgaard, R. Froese, and F. Torres. 1998. Fishing down marine food webs. Science 279:860-863.

Robinson, C. L. K., and D. M. Ware. 1994. Modelling pelagic fish and plankton trophodynamics off southwestern Vancouver Island, British Columbia. Canadian Journal of Fisheries and Aquatic Sciences 51:1737-1751.

Robinson, C. L. K., and D. M. Ware. 1999. Simulated and observed response of the southwest Vancouver Island pelagic ecosystem to oceanic conditions in the 1990s. Canadian Journal of Fisheries and Aquatic Sciences 56:2433-2443.

Robinson, C. L. K., D. M. Ware, and T. R. Parsons. 1993. Simulated annual plankton production in the northeastern Pacific Coastal Upwelling Domain. Journal of Plankton Research 15:161-183.

Rose, K. A., B. A. Megrey, F. Werner, and D. M. Ware. 2007. Calibration of the NEMURO nutrient-phytoplanktonzooplankton food web model to a coastal ecosystem: evaluation of an automated calibration approach. Ecological Modelling 202:38-51.

Rose, K. A., E. S. Rutherford, D. S. McDermot, J. L. Forney, and E. L. Mills. 1999. Individual-based model of yellow perch and walleye populations in Oneida Lake. Ecological Monographs 69:127-154.

Rudstam, L. G. 1988. Exploring the dynamics of herring consumption in the Baltic: applications of an energetic model of fish growth. Kieler Meeresforschungen Sonderheft 6:312-322.

Runge, J. A., P. J. S. Franks, W. C. Gentleman, B. A. Megrey, K. A. Rose, F. E. Werner, and B. Zakardjian. 2005. 
Diagnosis and prediction of variability in secondary production and fish recruitment processes: developments in physical-biological modeling. Pages 413-473 in A. R. Robinson and K. H. Brink, editors. Global coastal ocean: multiscale interdisciplinary processes. Harvard University Press, Cambridge, Massachusetts.

Schweigert, J. 2004. Stock assessment for British Columbia herring in 2003 and forecasts of the potential catch in 2004. Canadian Science Advisory Secretariat Research Document 2004/005. Available: www.dfo-mpo.gc.ca/ csas/. (June 2005).

Schweigert, J., F. Funk, K. Oda, and T. Moore. 2002. Herring size-at-age variation in the North Pacific. Pages 47-57 in Report of 2001 bass/model, monitor and rex workshops, and the 2002 model/rex workshop. North Pacific Marine Science Organization (PICES), Sidney, British Columbia.

Schweigert, J., and R. Tanasichuk. 1999. An evaluation of the natural mortality rate used in the assessment of British Columbia herring stocks. Canadian Science Advisory Secretariat Research Document 99/22. Available: www. dfo-mpo.gc.ca/csas/. (June 2005).

Stocker, M. 1993. Recent management of the British Columbia herring fishery. Canadian Bulletin of Fisheries and Aquatic Sciences 226:267-293.

Stokesbury, K. D. E., J. Kirsch, E. V. Patrick, and B. L. Norcross. 2002. Natural mortality estimates of juvenile Pacific herring (Clupea pallasi) in Prince William Sound, Alaska. Canadian Journal of Fisheries and Aquatic Sciences 59:416-423.

Tanasichuk, R. W. 1997. Influence of biomass and ocean climate on the growth of Pacific herring (Clupea pallasi) from the southwest coast of Vancouver Island. Canadian Journal of Fisheries and Aquatic Sciences 54:2782-2788.
Tanasichuk, R. W. 2000. Age-specific natural mortality rates of adult Pacific herring (Clupea pallasi) from southern British Columbia. Canadian Journal of Fisheries and Aquatic Sciences 57:2258-2266.

Tanasichuk, R. W. 2002. Implications of interannual variability in euphausiid population biology for fish production along the southwest coast of Vancouver Island: a synthesis. Fisheries Oceanography 11:18-30.

Tyler, J. A., and K. A. Rose. 1994. Individual variability and spatial heterogeneity in fish population models. Reviews in Fish Biology and Fisheries 4:91-123.

Wainwright, T. C., L. R. Feinberg, R. C. Hooff, and W. T. Peterson. 2007. A comparison of two lower trophic models for the California Current system. Ecological Modelling 202:120-131.

Ware, D. M., and J. Schweigert. 2002. Metapopulation dynamics of British Columbia herring during cool and warm climate regimes. Canadian Science Advisory Secretariat Research Document 2002/107. Available: www.dfo-mpo.gc.ca/csas/. (June 2005).

Williams, E. H., and T. J. Quinn. 2000a. Pacific herring, Clupea pallasi, recruitment in the Bering Sea and northeast Pacific Ocean, I. Relationships among different populations. Fisheries Oceanography 9:285-299.

Williams, E. H., and T. J. Quinn. 2000b. Pacific herring, Clupea pallasi, recruitment in the Bering Sea and northeast Pacific Ocean, II. Relationships to environmental variables and implications for forecasting. Fisheries Oceanography 9:300-315.

Yamanaka, Y., N. Yoshie, M. Fuijii, M. Aita-Noguchi, and M. J. Kishi. 2004. An ecosystem model coupled with nitrogen-silicon-carbon cycles applied to Station A7 in the Northwest Pacific. Journal of Oceanography 60:227241. 